\title{
Dense Ceramic NTC Thermistor Films Produced at Room Temperature by the Novel Aerosol Deposition Method (ADM) for Temperature Sensor Applications
}

Michaela Bruckner ${ }^{1}$, Christian Münch ${ }^{2}$, Sophie Schuurman ${ }^{3}$, Veronique Poulain ${ }^{3}$, Jaroslaw Kita ${ }^{1}$, Ralf Moos ${ }^{1}$

${ }^{1}$ Lehrstuhl für Funktionsmaterialien, Universität Bayreuth, 95440 Bayreuth, Germany

2 Vishay Electronic GmbH, Dr.-Felix-Zandman-Platz 1, 95100 Selb, Germany

${ }^{3}$ Vishay Resistors Belgium BVBA, Twee Huizenstraat 37, 1140 Brussel (Evere), Belgium

\begin{abstract}
In this work, we present a novel spray coating process called aerosol deposition method (ADM) to produce dense ceramic NTCR films at room temperature directly from the initial spinel-type ceramic powder on different substrate materials for temperature sensor applications. Measurements between $25^{\circ} \mathrm{C}$ and $85^{\circ} \mathrm{C}$ demonstrate the good behavior.
\end{abstract}

Key words: Temperature sensor, NTC thermistor, thick film, aerosol deposition method (ADM), room temperature

\section{Introduction}

Nickel manganese oxides are well-known semiconducting ceramics whose electrical resistance decreases exponentially with increasing temperature. Due to their high (negative) temperature coefficient of resistance (NTCR), low cost and reliability, they are well suited and widely used for temperature sensor applications. Conventional NTC thermistors are produced by methods like pressing, extrusion or film casting followed by a sintering step. These methods are very time-consuming and energyintensive. In addition, due to the poor sinterability of the NTCR ceramics, pores and poor intergranular contacts occur. They lead to problems in the stability and reproducibility of the NTC thermistors. A process that can circumvent these disadvantages is the aerosol deposition method (ADM). The ADM is a novel spray coating process to produce dense ceramic films at room temperature directly from the initial ceramic powder on various substrate materials [1]. An apparatus, which is typically used for the ADM consist of a deposition chamber, a vacuum pump, a nozzle and an aerosol generation unit. A schematic set up of an ADM apparatus is shown in Fig. 1. In the aerosol generation unit, for example a fluidized bed, a particle aerosol is generated by passing a carrier gas (e.g. oxygen, nitrogen) through a loose powder. Driven by a pressure difference between the aerosol generation unit and the deposition chamber, the particle aerosol is transported into the deposition chamber. During passing the nozzle, the particles are accelerated up to several hundred meters per second. In the deposition chamber, the particles collide with the substrate (e.g. ceramic, metal or polymer). Thereby, suitable particles break up and / or deform plastically and form a firmly adhering ceramic film [1].

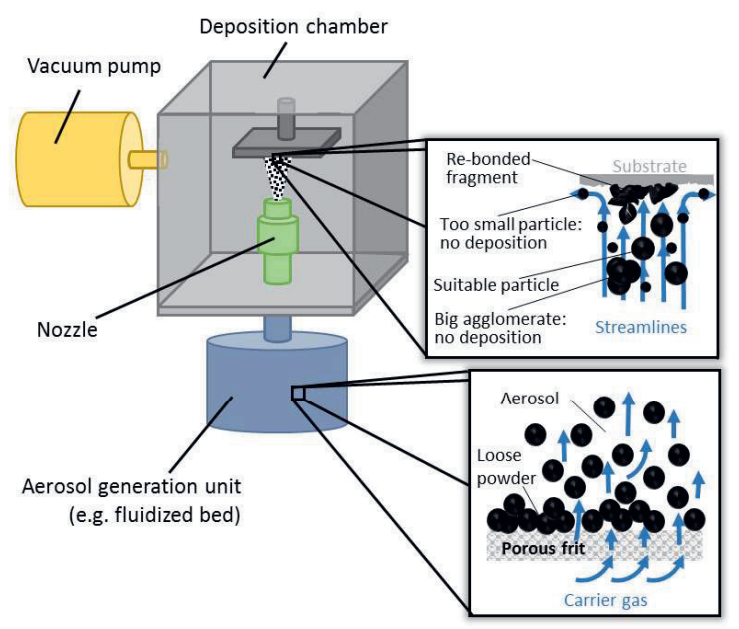

Fig. 1. Schematic set up of an apparatus for the aerosol deposition method (ADM) and representation functional principle

Using the ADM, ceramic films in a typical thickness range of $0.5 \mu \mathrm{m}$ up to $30 \mu \mathrm{m}$ with a high density, a nanocrystalline film structure, and comparable properties as bulk ceramics, can be produced. 


\section{Experimental Method}

The $\mathrm{NiMn}_{2} \mathrm{O}_{4}$ starting powder for the ADM was prepared via the mixed oxide route using commercial $\mathrm{NiO}$ and $\mathrm{Mn}_{2} \mathrm{O}_{3}$ ceramic powder. The calcination was carried out in an electrical furnace at $900{ }^{\circ} \mathrm{C}$ for $3 \mathrm{~h}$ in air atmosphere. For a better deposition behavior, the powder was milled in a rotary ball mill at $400 \mathrm{rpm}$ for 30 minutes. The milling was carried out in zirconia grinding bars with zirconia milling balls in deionized water. Subsequently, the powders were dried and sieved in order to minimize powder agglomeration, which has a negative influence on the deposition behavior. The crystal structure of the powder was analyzed by XRD.

In the second step of the study, the aerosol deposition of the prepared powder took place. The deposition is carried out on rigid substrates such as alumina, steel and silicon as well as on flexible substrates such as polyimide tapes. The electrical characterization was conducted on films deposited on alumina substrates with screen-printed AgPd-electrode structures (4wire-transducer [2]).

The films were characterized in the deposited state via SEM, XRD, and electrical measurement. The electrical resistance was measured between $25^{\circ} \mathrm{C}$ and $90^{\circ} \mathrm{C}$ in a highprecision thermostatic bath (Julabo SL-12) with silicone oil (DOW CORNING® 200 FLUID, 5 CST). For temperature control, a high precision Pt1000 was used. The data evaluation was performed with respect to the $\rho_{25}$ and $B$ value. $\rho_{25}$ is the specific resistance at $25^{\circ} \mathrm{C}$ and is calculated from the resistance at $25^{\circ} \mathrm{C}\left(R_{25}\right)$ and the geometrical details of the NTC thermistor. $B$ is an energetic constant which can be regarded as a factor for thermal sensitivity [3]. For the calculation, the following equation was used [4]:

$B=\frac{T_{25} \cdot T_{85}}{T_{85}-T_{25}} \cdot \ln \left(\frac{R_{25}}{R_{85}}\right)$

Where $T_{25}$ and $T_{85}$ are $25^{\circ} \mathrm{C}$ und $85^{\circ} \mathrm{C}$ as well as $R_{25}$ and $R_{85}$ are the resistance at $25^{\circ} \mathrm{C}$ and $85^{\circ} \mathrm{C}$.

\section{Results}

The XRD pattern of the prepared powder confirmed the desired single-phase cubic $\mathrm{NiMn}_{2} \mathrm{O}_{4}$ spinel. The aerosol deposition of the prepared powder was successful on alumina, steel and silicon as well as on the flexible polyimide tapes. The films are homogenous, scratch resistant and about $1 \mu \mathrm{m}$ thick. A detailed analysis of a NTCR film on an alumina substrate by SEM is shown in Fig. 2.

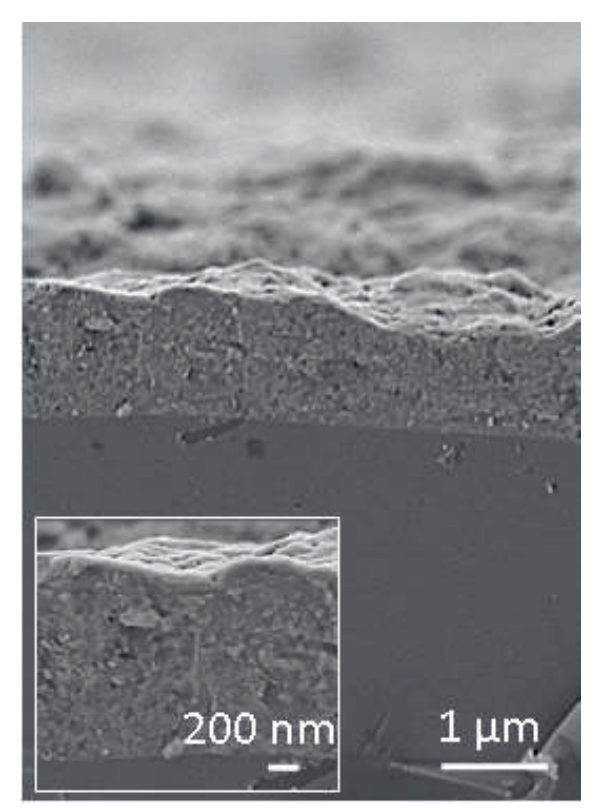

Fig. 2. SEM image of the fracture surface of a NTCR NiMn ${ }_{2} \mathrm{O}_{4}$ thick film on alumina substrate

The SEM image in Fig. 2 shows a nanocrystalline $\mathrm{ADM} \mathrm{NiMn} \mathrm{O}_{4}$ thick film on an alumina substrate. The film is homogenous and about $1 \mu \mathrm{m}$ thick. There are no visible cracks or pores in the $\mathrm{NiMn}_{2} \mathrm{O}_{4}$ thick film so that a completely dense ADM film can be obtained. The adhesion of the film to the substrate is very good, which is confirmed by the scratch resistance of the NTCR film. The XRD patterns of the ADM thick film on silicon substrate show the identical single-phase cubic $\mathrm{NiMn}_{2} \mathrm{O}_{4}$ spinel as that of the starting powder. Consequently, no phase change occurs during the aerosol deposition process.

The electrical characterization of the $\mathrm{NiMn}_{2} \mathrm{O}_{4}$ films on alumina substrates with screen-printed AgPd-electrode structures (4-wire-transducer [2]) shows the typical NTCR behavior, i.e., the resistance decreases exponentially with increasing temperature. The calculated specific resistance $\rho_{25}$ is about $65 \Omega \mathrm{m}$ and the constant $B$ amounts to $4250 \mathrm{~K}$. Both are close to commercial bulk values with $20-30 \Omega \mathrm{m}$ und $3500 \mathrm{~K}-3900 \mathrm{~K}$ [5-8]. Also, the reproducibility of the ADM process is very good. For identical manufacturing parameters the $\rho_{25}$ and $B$ values for different samples are equal. 

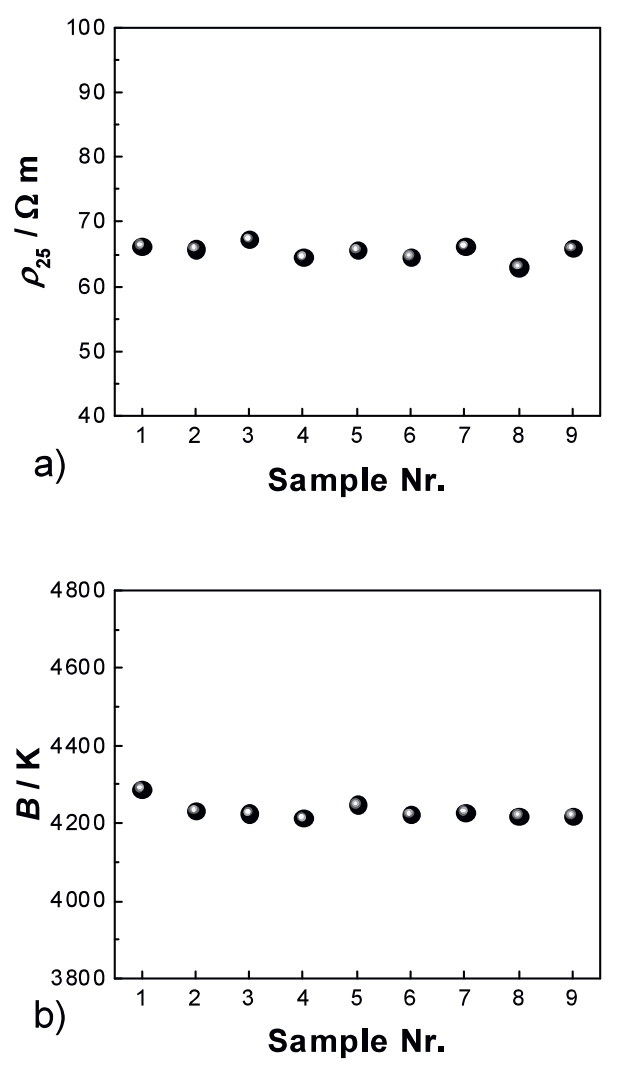

Fig. 3. Calculated a) $\rho_{25}$ values and b) $B$ values of nine different NTCR films on alumina with screen printed AgPd electrode structure prepared with identical process parameters

\section{References}

[1] D. Hanft, J. Exner, M. Schubert, T. Stöcker, P. Fuierer, R. Moos, An Overview of the Aerosol Deposition Method: Process Fundamentals and New Trends in Materials Applications, J. Ceram. Sci. Technol. 6, 147-182 (2015), doi: 10.4416/JCST2015-00018

[2] G. Hagen, J. Kita, N. Izu, U. Röder-Roith, D. Schönauer-Kamin, R. Moos, Planar platform for temperature dependent four-wire impedance spectroscopy-A novel tool to characterize functional materials, Sensors and Actuators B: Chemical 187, 174-183 (2013), doi: 10.1016/j.snb.2012.10.068

[3] H. Han, J. S. Lee, J. H. Ryu, K. M. Kim, J. L. Jones, J. Lim, S. Guillemet-Fritsch, H. C. Lee, S. Mhin, Effect of High Cobalt Concentration on Hopping Motion in Cobalt Manganese Spinel Oxide $\left(\mathrm{Co}_{x} \mathrm{Mn}_{3-\mathrm{x}} \mathrm{O}_{4}, \mathrm{x} \geq 2.3\right)$, J. Phys. Chem. C 120, 13667-13674 (2016), doi: 10.1021/acs.jpcc.6b01440

[4] K. Park, D. Y. Bang, Electrical properties of Ni$\mathrm{Mn}-\mathrm{Co}-(\mathrm{Fe})$ oxide thick-film NTC thermistors prepared by screen printing, J. Mater. Sci.: Materials in Electronics 14, 81-87 (2003), doi: 10.1023/A:1021900618988
Thus, Fig. 3 shows the results of the electrical characterization of nine identically prepared NTCR films on alumina substrates with screenprinted $\mathrm{AgPd}$ electrode structure. Both the $\rho_{25}$ values (Fig. 3 a)) and the $B$ values (Fig. 3 b)) of the nine samples are in good agreement.

\section{Conclusion}

The study showed that a successful deposition of $\mathrm{NiMn}_{2} \mathrm{O}_{4}$ powder on various substrate materials is possible. The deposited films are nanocrystalline, dense and have a good substrate adhesion. The X-ray diffraction confirms that no phase change occurs during the deposition process. The electrical characterization shows the typical NTCR behavior of the ADM films. The calculated $\rho_{25}$ and $B$ values can be produced reproducibly and are close to the value of the classical bulk $\mathrm{NiMn}_{2} \mathrm{O}_{4}$ NTC thermistors.

[5] D.-I. Fang, Z.-b. Wang, P.-h. Yang, W. Liu, C.-s. Chen, A. J. A. Winnubst, Preparation of UltraFine Nickel Manganite Powders and Ceramics by a Solid-State Coordination Reaction, J. Am. Ceram. Soc. 89, 230-235 (2006), doi: 10.1111/j.1551-2916.2005.00666.x

[6] H. Gao, C. Ma, B. Sun, Preparation and characterization of $\mathrm{NiMn}_{2} \mathrm{O}_{4}$ negative temperature coefficient ceramics by solid-state coordination reaction, J. Mater. Sci. - Mater. Electron. 25, 3990-3995 (2014), doi: 10.1007/s10854-0142118-5

[7] A. Feltz, J. Töpfer, F. Schirrmeister Conductivity data and preparation routes for $\mathrm{NiMn}_{2} \mathrm{O}_{4}$ thermistor ceramics, J. Eur. Ceram. Soc. 9, 187191 (1992), doi: 10.1016/0955-2219(92)90004-W

[8] S. M. Savic, M. V. Nikolic, O. S. Aleksic, M. Slankamenac, M. Zivanov P. M. Nikolic, Intrinsic resistivity of sintered Nickel Manganite vs. powder activation time and density, Sci Sintering 40, 27-32 (2008), doi: 10.2298/SOS0801027S 